\title{
Characterization of a new open jet wind tunnel to optimize and test vertical axis wind
} turbines

Tourn, Silvana; Pallares, Jordi; Cuesta, Ildefonso; Schmidt Paulsen, Uwe

Published in:

Journal of Renewable and Sustainable Energy

Link to article, DOI:

$10.1063 / 1.4982750$

Publication date:

2017

Document Version

Publisher's PDF, also known as Version of record

Link back to DTU Orbit

Citation (APA):

Tourn, S., Pallares, J., Cuesta, I., \& Schmidt Paulsen, U. (2017). Characterization of a new open jet wind tunnel to optimize and test vertical axis wind turbines. Journal of Renewable and Sustainable Energy, 9(3), [033302]. https://doi.org/10.1063/1.4982750

\section{General rights}

Copyright and moral rights for the publications made accessible in the public portal are retained by the authors and/or other copyright owners and it is a condition of accessing publications that users recognise and abide by the legal requirements associated with these rights.

- Users may download and print one copy of any publication from the public portal for the purpose of private study or research.

- You may not further distribute the material or use it for any profit-making activity or commercial gain

- You may freely distribute the URL identifying the publication in the public portal 


\title{
Characterization of a new open jet wind tunnel to optimize and test vertical axis wind turbines
}

\author{
Silvana Tourn, ${ }^{1}$ Jordi Pallarès, ${ }^{1, a)}$ Ildefonso Cuesta, ${ }^{1}$ and \\ Uwe Schmidt Paulsen ${ }^{2}$ \\ ${ }^{1}$ Departament d'Enginyeria Mecànica, Universitat Rovira i Virgili, Av. Països Catalans 26, \\ 43007 Tarragona, Spain \\ ${ }^{2}$ Department of Wind Energy, Technical University of Denmark, Frederiksborgvej 399, \\ DK-4000 Roskilde, Denmark
}

(Received 12 June 2016; accepted 17 April 2017; published online 2 May 2017)

\begin{abstract}
Based on the increasing interest in urban environmental technologies, the study of small scale vertical axis wind turbines shows motivating challenges. In this paper, we present the characteristics and potentials of a new open jet wind tunnel. It has a nozzle exit area of $1.5 \times 1.5 \mathrm{~m}^{2}$, and it can be operated with exit velocities from $3 \mathrm{~m} / \mathrm{s}$ to $17 \mathrm{~m} / \mathrm{s}$. The characterization of the flow has been carried out with calibrated pitot tubes, cup anemometers, and hot wire anemometers. Two different configurations of the test area, with and without a ceiling, are considered. Measurements in the range of available exit velocities show that the cross section, where the velocity and turbulence intensities show an acceptable level of uniformity, has an area of $0.8 \times 0.8 \mathrm{~m}^{2}$ and a streamwise dimension of $2 \mathrm{~m}$ from the nozzle exit of the tunnel. In this working section, the maximum turbulence intensity is $4 \%$. The detailed characterization of the flow carried out indicates that the wind tunnel can be used to test small scale models of wind turbines. Published by AIP Publishing. [http://dx.doi.org/10.1063/1.4982750]
\end{abstract}

\section{INTRODUCTION}

A wind tunnel is an important experimental tool in fluid engineering. It is often a rapid and accurate tool to conduct aerodynamic research, to support design decisions, and to validate numerical flow simulations. Here, we built an open jet wind tunnel (OJWT) without a collector and with 4 axial fans. The experimental equipment was designed with aerodynamic concepts using a combination of empirical data and theoretical calculations. The new facility with a nozzle exit area of $1.5 \times 1.5 \mathrm{~m}^{2}$ is a useful tool to study models of urban vertical axis wind turbines (VAWTs).

Compared to traditional wind tunnel testing, an open jet wind generating facility offers supplementary capabilities and features for testing compared to high cost atmospheric boundary layer $(\mathrm{ABL})$ wind tunnels or special purpose built wind tunnels. This configuration allows the use of high blockage ratios, it provides excellent access to the model, and it facilitates flow field measurements. ${ }^{1,2}$ The available literature presents the studies of wind turbines using OJWTs. Some of them include the analysis of the wake of the turbine, ${ }^{3}$ and others have investigated the aerodynamic performances of blades of a small-scale VAWT ${ }^{4}$ and tested several full-scale, wind-turbine airfoils, at various speeds (high Reynolds numbers) and angles of attack. ${ }^{5}$ Similar to VAWTs, marine hydrokinetic turbines ${ }^{6,7}$ extract mechanical power from moving water, and analyses can be performed in towing tanks. Most of the studies dealing with VAWTs consider Darrieus type turbines, ${ }^{8}$ which show a larger efficiency than Savonius type turbines and can be installed onshore and offshore. ${ }^{9}$

\footnotetext{
${ }^{a)}$ Author to whom correspondence should be addressed. Electronic mail: jordi.pallares@urv.cat. Tel.: +34 977559682.
} 
In the majority of turbulent jets studied theoretically or experimentally, the wind speed is assumed uniform and constant at the outlet of the nozzle. In OJWTs, a uniform flow can be achieved just at the exit of the nozzle, i.e., in the potential core. Reference 3 presented the study of the evolution of the wake of a horizontal axis wind turbine (rotor diameter of $0.6 \mathrm{~m}$ ) in an open-jet wind-tunnel installed at the Delft University of Technology (The Netherlands). This facility has an outlet diameter of $3 \mathrm{~m}$ that is placed in a large room with a width of $13 \mathrm{~m}$ and a height of $8 \mathrm{~m}$. It can handle very large models that obstruct airflow quite considerably. Reference 4 employed zero-net mass flux (ZNMF) actuation on an H-type VAWT blade. The application of the ZNMF technique was found to have a beneficial effect on the blade's aerodynamic performance by either suppressing dynamic stall or delaying its onset to higher angles of attack. Reference 5 analyzed the flow and acoustic measurements around wind-turbine airfoils performed at the Virginia Tech Stability Wind Tunnel (United States of America). This unique facility is aerodynamically closed and acoustically open, which allows better aerodynamic performance than a free jet facility, while maintaining comparable acoustic performance. With a $1.83 \mathrm{~m}$ $\times 1.83 \mathrm{~m}$ test-section, it is one of the largest wind tunnels in the United States of America with a maximum speed of $80 \mathrm{~m} / \mathrm{s}$. The aerodynamic capabilities were recently increased by the addition of a removable anechoic test-section, allowing for full-scale aero-acoustic testing.

A number of analyses deal with exploring the quality of the flow (mean flow, velocity profile, and turbulence/spectral representation) ${ }^{10-12}$ An important incitement is made by the wind power industry, supporting actions in investigating the appropriateness of wind tunnels for calibration of cup anemometers, as defined, for example, by the Measuring Network of Wind Energy Institutes (MEASNET) and wind turbine power performance measurement standards (see, for example, the standard IEC61400-12-1/2005 by the International Electrotechnical Commission). The cup anemometer is presently the accepted wind sensor to be used in wind turbine power performance accredited measurements. Some of the challenges are to comply with international standards and to overcome uncertainties originating from (i) the determination of the undisturbed (free) wind in the empty tunnel, (ii) the presence of the cup anemometer inducing blockage, (iii) the quality of the flow within the measurement volume of the cup anemometer, (iv) the mounting setup, and (v) the test section design and setup.

The present paper deals with the characterization of an OJWT designed with a relatively low budget to be installed in a relatively limited physical space. First, the design concept is discussed, and the initial and updated design criteria are explained. The aerodynamic design and selection of the wind tunnel components are discussed in detail. The analyses of the exit flow uniformity and turbulence characteristics of the OJWT without and with a false ceiling in the test area where the jet is expanded are reported. Finally, cup anemometer calibration results without and with the false ceiling to improve the test area are presented in order to complete the characterization of the new facility and to show the quality of the flow in the test section (i.e., uniform velocity and low turbulence intensity).

\section{DESIGN}

The wind tunnel was designed considering the dimensions of typical urban VAWTs. The validity of the tests in a tunnel with a scale model requires the validity of the geometric, kinematic, and dynamic similarities between the flow around the model and the flow around the real turbine under specific atmospheric conditions. This means that the model has to be a replica of the real turbine and should also present certain dimensionless parameters equal in both flows, i.e., between the flow under real atmospheric conditions and the flow generated in the wind tunnel. The Reynolds number is the relevant parameter for an incompressible subsonic flow wind tunnel.

With the dimensions of the test section established, the required wind speed can be estimated. The maximum wind speed for the present wind tunnel was set to be about $15 \mathrm{~m} / \mathrm{s}$ for a hydraulic diameter of the nozzle exit of $1.5 \mathrm{~m}$. Another design criterion is the quality of the flow in the test section, which depends on the uniformity of the flow and the levels of the turbulence intensity. The last parameter is less strict in tunnels for non-aeronautical testing. ${ }^{13}$ As a 
design objective, a value of turbulence intensity of about $5 \%$ in the test section was defined. The available space in the room to install the tunnel was $12 \mathrm{~m}$ in length, $5 \mathrm{~m}$ in width, and $4 \mathrm{~m}$ in height.

Different concepts of open jet wind tunnels can be found in the literature. Some of them have a closed-circuit design with a closed or a semi-closed test section, from which the air flow exiting the nozzle comes into the collector. ${ }^{14,15}$ Others are open circuit tunnels where the open jet from the nozzle is expanded freely into the laboratory. ${ }^{16,17}$ The concept of the open jet wind tunnel without a collector has the advantages of being lower cost and requiring less space. Based on these studies, we decided to design the wind tunnel as an open-circuit tunnel with components and dimensions indicated in Figure 1. The tunnel, named "4-Winds" and installed in the laboratories of the University Rovira i Virgili (Tarragona, Spain), is an open jet type

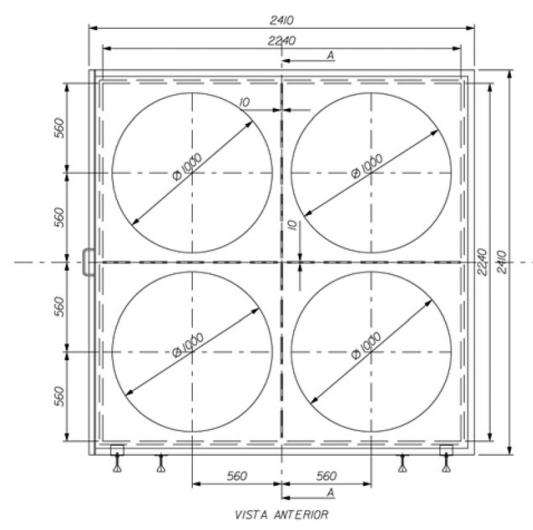

(a)
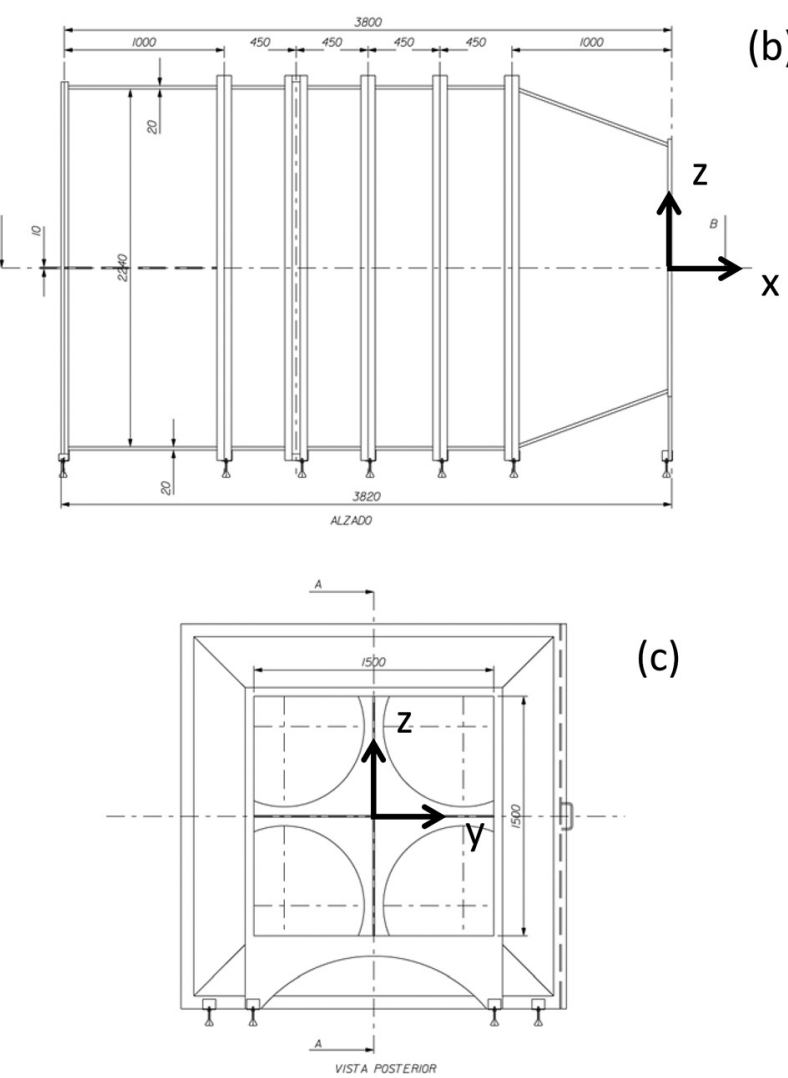

(c)

FIG. 1. Sketch of the wind tunnel layout: (a) back view, (b) side view, and (c) front view. Dimensions are in millimeters. 
tunnel, powered by 4 fans with an open test section and an open circuit. The elements of this wind tunnel are (in the direction of the flow) fans, plenums, flow straighteners, and conditioning elements, a contraction and test section. The flow is impelled by four fans of $7.5 \mathrm{~kW}$ each, with a diameter of $1 \mathrm{~m}$ and placed in a $2.24 \mathrm{~m} \times 2.24 \mathrm{~m}$ matrix (see Fig. 1(a)). The fans feed $1 \mathrm{~m}$ long plenum chambers with a safety screen at the end. A honeycomb and two grids are placed windward to reduce the flow turbulence intensity and increase the flow uniformity. All these elements complete the settling chamber of the facility. They can be easily removed for maintenance. Finally, the open jet exits into the test section from a nozzle, with a contraction with a ratio of 2.23 and a length of $1 \mathrm{~m}$, to increase the flow speed.

The aerodynamic considerations were established once the general layout was defined. The size of the nozzle exit is based on the solid blockage effect, and this defines the dimensions of the other components of the wind tunnel. Solid blockage is often computed as the ratio of the frontal area of the object and the cross section of the wind tunnel, ${ }^{2}$ and it is usually expressed in percentage. Taking into account the frontal swept area of a model of a urban VAWT, i.e., around $0.5 \mathrm{~m} \times 0.5 \mathrm{~m}$, a nozzle exit cross section $(1.5 \mathrm{~m} \times 1.5 \mathrm{~m})$ was defined and resulted in a blockage ratio of around $11 \%$. The blockage effect influences the flow around the model, and it is more pronounced in tunnels with confined test sections than in open jet wind tunnels where the flow can more easily move around the tested body. For example, the blockage ratio in the measurements of the power curves of a Darrieus-type VAWT performed by Howell et al. ${ }^{18}$ in a closed wind tunnel was $7.5 \%$. Mertens ${ }^{2}$ and van Bussel ${ }^{19}$ carried out experiments in open jet wind tunnels with blockages (100 swept area/nozzle exit) of 5\% and 14\%, respectively. In any case, the blockage can be reduced, for example, down to $7 \%$ using models with a swept area of $0.4 \times 0.4 \mathrm{~m}^{2}$. The 4 -Winds OJWT has a square-to-square contraction and a square cone shape. A jet with a maximum speed of approximately $15 \mathrm{~m} / \mathrm{s}$ in the test section was proposed. The power of the driving fan was estimated using the maximum speed and the summation of pressure losses in the wind tunnel components, i.e., the total pressure drop $(\Delta P)$ along the wind tunnel sections. The loss in a section is defined as the mean loss of total pressure sustained by the stream in passing through the particular section. The loss in a section is given in a dimensionless form by the ratio of the pressure loss in the section to the dynamic pressure at the entrance to the section. ${ }^{20}$ For a typical "local" section, this is given by Equation (1)

$$
K_{l}=\frac{\Delta P_{l}}{\frac{1}{2} \rho_{l} u_{l}^{2}} .
$$

The calculated sum of the pressure loss of the wind tunnel components at a speed of $15 \mathrm{~m} / \mathrm{s}$ indicated a necessary pressure increase of approximately $300 \mathrm{~Pa}$. Estimations of the pressure loss coefficients were taken from Refs. 21-23.

The passages of the honeycomb have a diameter $D_{h}$ of $5 \mathrm{~mm}$, and a honeycomb thickness in the flow direction $L_{h}$ is $50 \mathrm{~mm}$. The honeycomb is a guiding device through which the individual air filaments are rendered parallel. ${ }^{20}$ Essentially, the honeycomb cells inhibit the lateral components of turbulence. This is achieved with length equivalent to about 5-10 cell diameters. ${ }^{24}$ In the facility under discussion, the length is equivalent to 10 cell diameters $D_{h}$. The wire meshes reduce the velocity deviations and the turbulence of the flow. Based on the wire Reynolds numbers given by Pope and $\mathrm{Ra}^{20}$ for standard air, a safety screen with a mesh aperture of $5 \mathrm{~mm}$ and a wire diameter of $2 \mathrm{~mm}$ was positioned in the plenum chambers. It provides the necessary protection for the fan. Two turbulence control screens with a mesh aperture of $1.81 \mathrm{~mm}$ and a wire diameter of $0.5 \mathrm{~mm}$ were installed upstream the honeycomb. Applying the design guidelines given by Mehta and Bradshaw, ${ }^{24}$ the distance between screens is found to be about 0.2 cross sectional diameters. The final component that reduces the turbulence intensity is the contraction nozzle. This reduction can be estimated by $1 / N^{2}$, with $N=S_{i n} / S_{0}$ being the contraction ratio. ${ }^{24}$ The shape and length of the contraction are not conventional. Special attention has been given to this component, and some conclusions have been developed throughout this publication. 


\section{ANALYSIS OF THE EXIT FLOW UNIFORMITY AND TURBULENCE CHARACTERISTICS}

The performance in terms of flow characteristics was measured with different instruments. The origin of the coordinate system is defined at the centre of the nozzle exit plane, and the $\mathrm{x}$-axis is aligned with the jet axis. The orientation of the $\mathrm{y}$-axis and the $\mathrm{z}$-axis is horizontal and vertical, respectively (see Fig. 1). The flow characteristics were analysed with a single hotwire probe. The signal from the straight probe 55P01 of DANTEC was sampled with 16-bit resolution and a sampling frequency of $20 \mathrm{kHz}$. It was processed to estimate the average speed $U$ and the intensity of the fluctuations $u^{\prime}$. A positioning system allowed the displacement of the probe along the three spatial directions. The measurements were taken at several planes parallel to the nozzle exit and along the jet axis to determine the flow uniformity and the turbulence intensities, and they will be subjected for similarity studies of velocity profiles in the planes and for further characterization of the tunnel on time scales.

\section{A. Effect of a false ceiling}

The test section was characterized in two different configurations. The first configuration corresponds to the conventional location of the tunnel with the floor located at $\mathrm{z}=-1.29 \mathrm{~m}$ and the ceiling of the laboratory at $\mathrm{z}=2.34 \mathrm{~m}$ (see Fig. 1). In the second configuration, a false ceiling located at $\mathrm{z}=1.29 \mathrm{~m}$ was installed above the test area to obtain symmetry of the flow with respect to the plane $\mathrm{z}=0$.

Figure 2 shows the time averaged scaled velocity profiles along the vertical z-direction and along the horizontal $y$-direction at $x=1 \mathrm{~m}$ without the false ceiling (Fig. 2(a)) and with the false ceiling (Fig. 2(b)), while Figure 3 shows the corresponding profiles at $x=2 \mathrm{~m}$. The profiles have been scaled using the measured velocity at the center of the nozzle exit. The specific values for the three different exit velocities are $5.0 \mathrm{~m} / \mathrm{s}, 11.0 \mathrm{~m} / \mathrm{s}$, and $14.4 \mathrm{~m} / \mathrm{s}$ for the profiles of Figure 2 and $5.4 \mathrm{~m} / \mathrm{s}, 11.0 \mathrm{~m} / \mathrm{s}$, and $15.0 \mathrm{~m} / \mathrm{s}$ for the profiles of Figure 3 . The distance between the locations of measurement is $0.1 \mathrm{~m}$. Red symbols show the mean velocities along the horizontal y-direction, and blue symbols correspond to velocities along the vertical z-direction. It can be seen that the velocity profiles with the false ceiling show more uniform profiles along the $y$-axis. The comparison of the velocities at the axis of the exit (i.e., $y=0$ and $\mathrm{z}=0$ ) indicates a velocity increment of about $0.5 \mathrm{~m} / \mathrm{s}$ with the ceiling. The ratio between the standard deviation $(\sigma)$ and average velocities in the regions $-0.5 \mathrm{~m} \leq \mathrm{y} \leq 0.5 \mathrm{~m}$ and $-0.5 \mathrm{~m} \leq \mathrm{z}$ $\leq 0.5 \mathrm{~m}$ is 0.01 . Note that the average velocities in the regions near $\mathrm{z}= \pm 0.6 \mathrm{~m}$ and $\mathrm{y}= \pm 0.6 \mathrm{~m}$ increase due to the relatively rapid contraction of the tunnel exit. Figure 3 shows the time averaged velocity profiles normalized along the vertical z-direction and along the horizontal $\mathrm{y}$-direction at $\mathrm{x}=2 \mathrm{~m}$ without the false ceiling (Fig. 3(a)) and with the false ceiling (Fig. 3(b)).

(a)

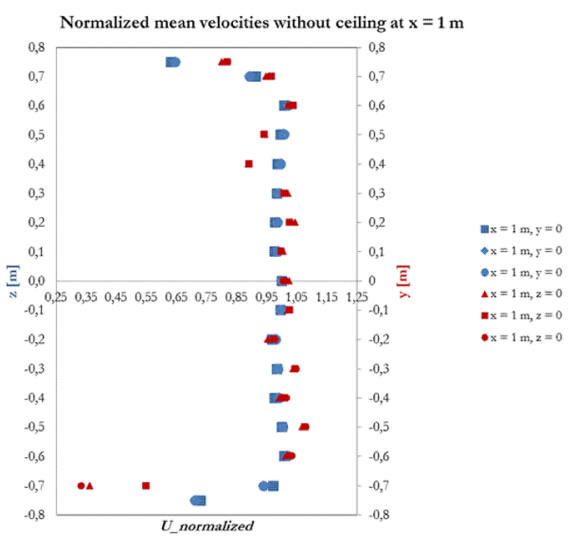

(b)

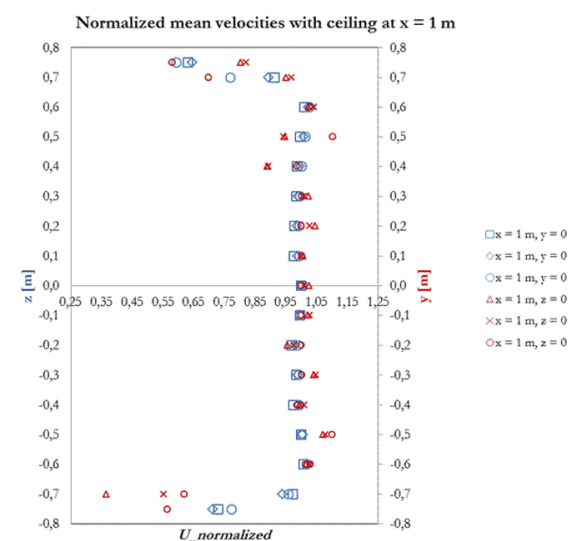

FIG. 2. Normalized average flow velocity profiles along the $\mathrm{z}$-vertical and $\mathrm{y}$-horizontal directions at $\mathrm{x}=1 \mathrm{~m}$ from the nozzle exit. (a) Profiles without a false ceiling and (b) profiles with a false ceiling. 
(a)

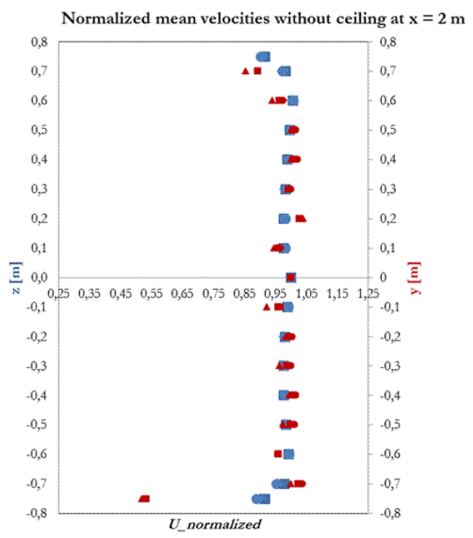

(b)

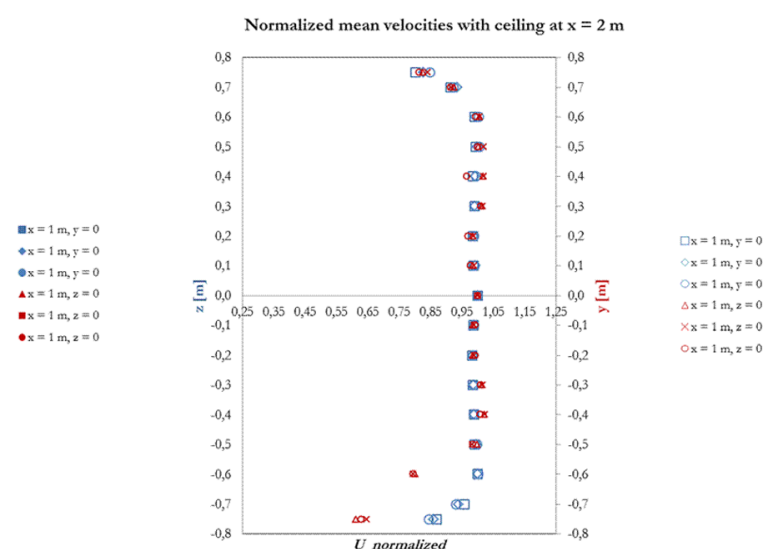

FIG. 3. Normalized average flow velocity profiles along the $\mathrm{z}$-vertical and $\mathrm{y}$-horizontal directions at $\mathrm{x}=2 \mathrm{~m}$ from the nozzle exit. (a) Profiles without a false ceiling and (b) profiles with a false ceiling.

At this position $(x=2 \mathrm{~m})$, a similar flow uniformity can be seen to that at $\mathrm{x}=1 \mathrm{~m}$ (Fig. 2). The ratio between the standard deviation $(\sigma)$ and average velocities in the regions $-0.5 \mathrm{~m} \leq \mathrm{y}$ $\leq 0.5 \mathrm{~m}$ and $-0.5 \mathrm{~m} \leq \mathrm{z} \leq 0.5 \mathrm{~m}$ is 0.01 .

The profiles of the turbulence intensities are shown in Figure $4(x=1 \mathrm{~m})$ and Figure 5 $(\mathrm{x}=2 \mathrm{~m})$. The turbulence intensity $(\mathrm{Ti})$ has been estimated considering the root mean square (RMS) of the signal of the single hot wire, which was oriented perpendicular to the flow during the experiments. The profiles are plotted along the $\mathrm{y}$ and $\mathrm{z}$ directions at three different mean velocities of the tunnel. It can be seen that at $x=1 \mathrm{~m}$ (Fig. 4), the false ceiling produces a more uniform distribution of the intensity of the velocity fluctuation and an overall reduction in the turbulence intensity of about $3 \%$ with respect to the case without the false ceiling. The measured velocity and turbulence intensity profiles indicate that the flow has a relatively constant velocity and a maximum turbulence intensity of $4 \%$ in a region with a cross sectional area of $0.8 \times 0.8 \mathrm{~m}^{2}$ and a streamwise dimension of $2 \mathrm{~m}$ from the exit of the tunnel.

Records of the flow at the locations $x=0, y=0, z=0$ and $x=1 \mathrm{~m}, \mathrm{y}=0$ and $\mathrm{z}=0$ were obtained with the hot-wire probe to analyse the spectral characteristics of the velocity signal for different velocities at the exit of the tunnel. Two time series at two different wind speeds with $60 \mathrm{~s}$ and $300 \mathrm{~s}$ durations were conditioned without a low-pass filter and sampled at 10 and $30 \mathrm{kHz}$, respectively (see Table I). The spectral analysis was conducted following the Welch method, ${ }^{25}$ using partitions of 800000 samples for the long and 60000 for the short time series,

(a)

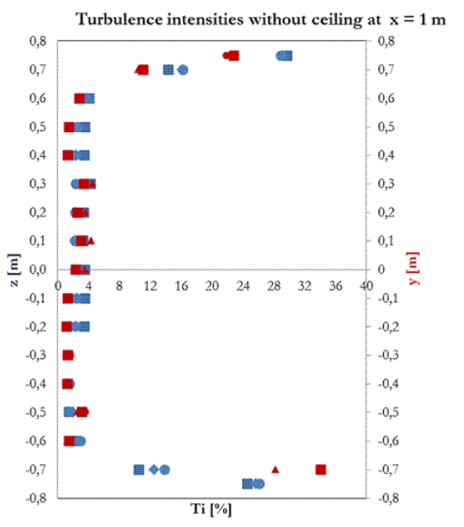

(b)

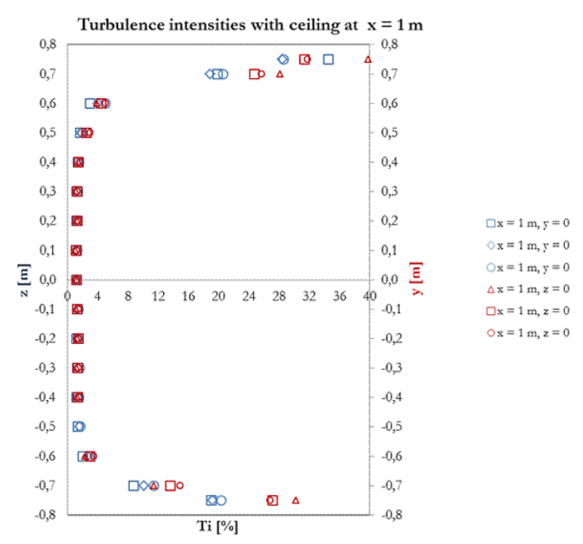

FIG. 4. Turbulence intensities along the $\mathrm{z}$-vertical and $\mathrm{y}$-horizontal directions at $\mathrm{x}=1 \mathrm{~m}$ from the nozzle exit. 
TABLE I. Measurement characteristics for spectral analysis.

\begin{tabular}{lccc}
\hline \hline Location & $\mathrm{U}(\mathrm{m} / \mathrm{s})$ & $f_{\text {acq }}(\mathrm{kHz})$ & $t_{s}(\mathrm{~s})$ \\
\hline $\mathrm{x}=1 \mathrm{~m}, \mathrm{y}=0, \mathrm{z}=0$ & 4.4 & 10 & 60 \\
$\mathrm{x}=0, \mathrm{y}=0, \mathrm{z}=0$ & 5.4 & 30 & 300 \\
$\mathrm{x}=1 \mathrm{~m}, \mathrm{y}=0, \mathrm{z}=0$ & 12.1 & 10 & 60 \\
$\mathrm{x}=0, \mathrm{y}=0, \mathrm{z}=0$ & 14.9 & 30 & 300 \\
\hline \hline
\end{tabular}

(a)

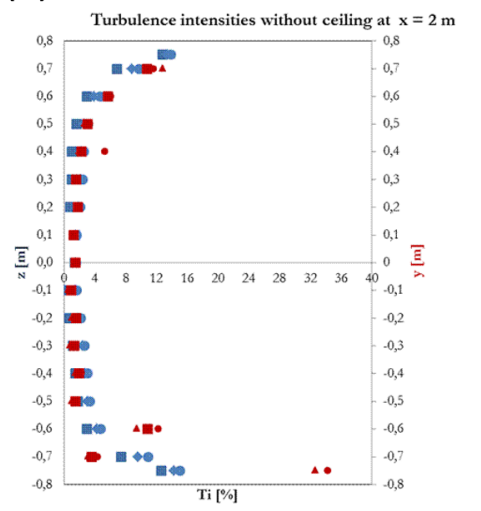

(b)

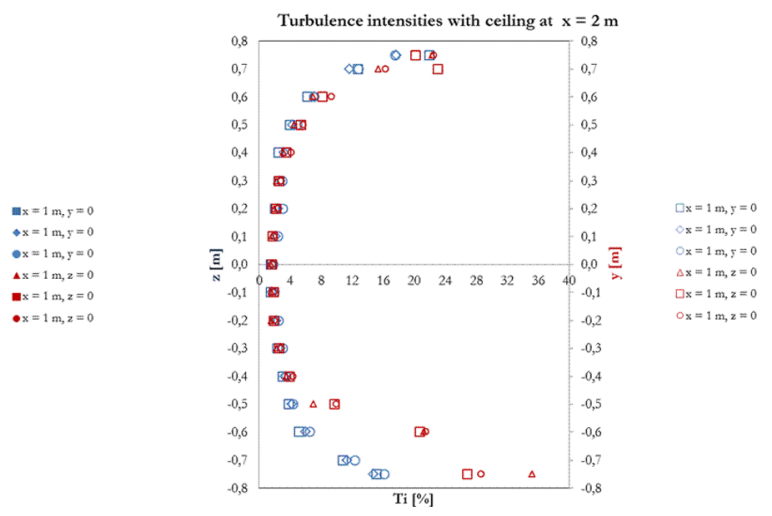

FIG. 5. Turbulence intensities along the $\mathrm{z}$-vertical and $\mathrm{y}$-horizontal directions at $\mathrm{x}=2 \mathrm{~m}$ from the nozzle exit.

respectively. Furthermore, the time series are low-pass filtered with a limit frequency of $500 \mathrm{~Hz}$, and after subtraction of the mean value $U$, the mean deviation hereafter is normalized with the standard deviation. Hereby, the variance of the normalized time series is equal to 1 . The power spectra are shown in Figure 6, together with the Davenport spectrum, ${ }^{26}$ Equation (2). The Davenport spectrum is considered as a good mathematical representation for the horizontal wind fluctuations

$$
p s d=\frac{2 / 3\left(f \frac{L u}{U}\right)^{2}}{\left(1+\left(f \frac{L u}{U}\right)^{2}\right)^{4 / 3}} .
$$

In Figure 6, the Davenport spectrum is fitted with a length scale $L u$ equal to $0.1 \mathrm{~m}$. The plot shows that, following Taylor's hypothesis of frozen turbulence, ${ }^{27,28}$ the standard deviation of the wind speed scales well with the averaged velocity. Additionally, the figure illustrates that the spectra increase at high frequencies, reflecting signal noise, which we have only partially removed by low-pass filtering. However, with Taylor's frozen turbulence assumption applied, the plots of the normalized spectra indicate that the spectra follow "normal atmospheric boundary layer $(\mathrm{ABL})$ turbulence" behaviour with a production range around $\mathrm{f} / \mathrm{U} \approx 10$ followed by an inertial subrange shown by a $-2 / 3$ slope. At high frequencies, the dissipation region is partly shown, but part is hidden by the high frequency noise. As demonstrated with the curve showing the Davenport spectrum, this spectral form reflects quite well the tunnel spectrum, provided that the production scale of the Davenport spectrum $(1200 \mathrm{~m})$ is replaced by the scale for the production scale for the tunnel turbulence $(\mathrm{Lu}=0.1 \mathrm{~m})$, reflecting vortices being created by means of propellers. This can be seen as an indication that the wind tunnel is suitable to study wind effects on a scaled wind turbine in a comparable way as with a real turbine operating in the ABL. Various studies are relevant to perform on VAWTs. As an example of understanding 


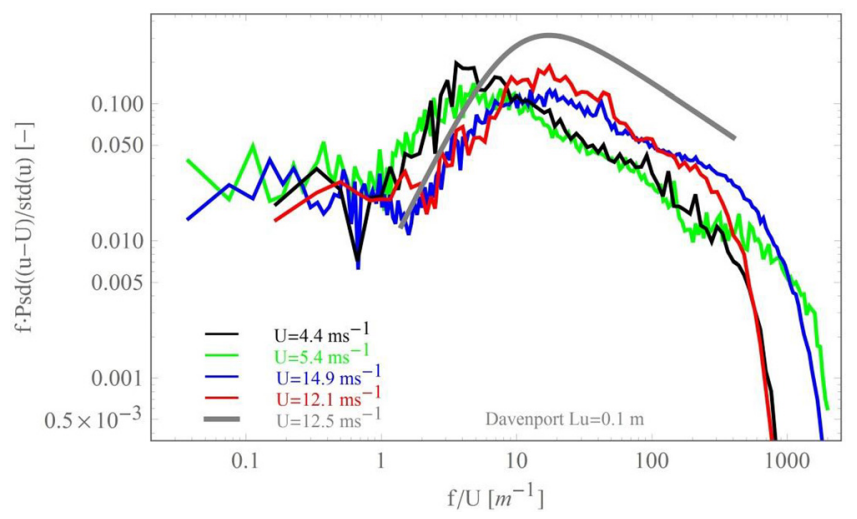

FIG. 6. Comparison of dimensionless spectra of the flow at the central axis of the wind tunnel.

the processes of energy conversion taking place in $\mathrm{ABL}$, the inflow and vorticity structure measured by a model VAWT in the open jet can produce valuable results in understanding turbulence and how this is linked, for example, to fluid dynamic simulation results. In this way, reduced scale modelling and wind load modelling can provide main physical parameters, as also pointed out in Ref. 12. A more specific investigation to be conducted is how mechanically created turbulence from an upwind sited rotor is transformed downwind, how the wake develops, and how the resulting inflow on the next turbine will affect the flow.

The characteristics of various existing open jet wind tunnels ${ }^{29-33}$ are summarized in Table II. The facilities shown in the table are used for research on wind turbines, aviation industries, and anemometry calibrations. Some of them include anechoic test sections for acoustic measurements and can generate high flow speeds and very low turbulence levels.

The 4-Winds OJWT has a similar purpose and similar characteristics to an open jet wind tunnel installed at the Delft University of Technology, as reported by Mertens. ${ }^{2}$ This wind tunnel is made of a large circular tube that encloses a fan at the suction side. The 4-Winds OJWT

TABLE II. Main characteristics of the open jet wind tunnels analyzed.

\begin{tabular}{|c|c|c|c|c|c|}
\hline Facility & $\begin{array}{l}\text { OJWT }^{\mathrm{a}} \mathrm{TU} \\
\text { Delft }\end{array}$ & $\begin{array}{l}\text { 4W-OJWT } \\
\text { Tarragona }\end{array}$ & S4 WT IDR/UPM ${ }^{\mathrm{b}}$ & OJ UNSW ${ }^{\mathrm{c}}$ & $\begin{array}{c}\text { SWT }^{\mathrm{d}} \text { Virginia } \\
\text { Tech }\end{array}$ \\
\hline Country & Nederland & Spain & Spain & Australia & U.S. \\
\hline Cross section & Circular & Square & Square & Circular & Square \\
\hline Test section size (m) & 2.24 diam. & $1.5 \times 1.5$ & $0.9 \times 0.9$ & 0.76 diam. & $1.83 \times 1.83$ \\
\hline Test section type & Open & Open & Closed/open ${ }^{\mathrm{e}}$ & Open & Closed/open ${ }^{\mathrm{e}}$ \\
\hline Tunnel length (m) & 10.85 & 4 & 12 & $\ldots$ & $\ldots$ \\
\hline Maximum tunnel speed (m/s) & 14 & 17 & 26 & 20 & 80 \\
\hline Non-uniformity of velocity (\%) & $7^{\mathrm{f}}$ & $5^{\mathrm{g}}$ & $\ldots$ & $\ldots$ & $\ldots$ \\
\hline Turbulence level (\%) & $0.8^{\mathrm{f}}$ & $1^{\mathrm{h}}$ & 0.2 & 0.2 & $0.01-0.03^{\mathrm{i}}$ \\
\hline
\end{tabular}

aJWT TU Delft: Open Jet Wind Tunnel, the Delft University of Technology. ${ }^{2}$

${ }^{\text {b}}$ S4 WT IDR/UPM: S4 Wind Tunnel, Instituto Universitario de Microgravedad Ignacio Da Riva/Universidad Politécnica de Madrid. ${ }^{33,34}$

'OJ UNSW: Open Jet, the University of New South Wales. ${ }^{32}$

${ }^{\mathrm{d}}$ SWT: Stability Wind Tunnel, Virginia Tech. ${ }^{35}$

${ }^{\mathrm{e}} \mathrm{Closed} /$ Open: The tunnel has a removable test section, i.e., it can be used as a closed test section or an open test section.

${ }^{\mathrm{f}}$ At a test section of $0.9 \times 1.2 \mathrm{~m}^{2}, 1.2 \mathrm{~m}$ downwind of the tunnel exit with a tunnel speed of $6 \mathrm{~m} / \mathrm{s}$.

${ }^{\mathrm{g}}$ At a test section of $0.8 \times 0.8 \mathrm{~m}^{2}, 1 \mathrm{~m}$ downwind of the tunnel exit at tunnel speeds between $5 \mathrm{~m} / \mathrm{s}$ and $15 \mathrm{~m} / \mathrm{s}$ (see Fig. 2(b)).

${ }^{\mathrm{h}}$ Maximum value at a test section of $0.8 \times 0.8 \mathrm{~m}^{2}, 1 \mathrm{~m}$ downwind of the tunnel exit at tunnel speeds between $5 \mathrm{~m} / \mathrm{s}$ and $15 \mathrm{~m} / \mathrm{s}$ (see Fig. 4(b)).

${ }^{\mathrm{i}}$ Turbulence levels are $0.016 \%$ at $12 \mathrm{~m} / \mathrm{s}$ and increase gradually with flow speed to $0.031 \%$ at $57 \mathrm{~m} / \mathrm{s} .{ }^{35}$ 
TABLE III. Relative errors between the averaged speeds measured with the pitot tubes and average speeds measured with the calibrated cup anemometer and pitot tubes with the cup anemometer placed in the working section.

\begin{tabular}{lcc}
\hline \hline & $\begin{array}{c}\text { Pitot tube }+ \text { Cup anem. } \\
\text { E \% } \%\end{array}$ & $\begin{array}{c}\text { Cup anem. } \\
\text { E \% }\end{array}$ \\
\hline Without ceiling & & \\
5.41 & 0.34 & 1.14 \\
7.32 & 0.36 & 0.86 \\
9.23 & 0.28 & 0.72 \\
11.17 & 0.08 & 0.71 \\
13.06 & 0.27 & 1.14 \\
14.98 & 0.07 & 1.74 \\
16.89 & 0.09 & 1.71 \\
& & \\
With ceiling & & 0.79 \\
5.47 & 0.23 & 0.47 \\
7.40 & 0.23 & 0.36 \\
9.33 & 0.24 & 0.36 \\
11.27 & 0.21 & 0.24 \\
13.20 & 0.25 & 0.32 \\
15.13 & 0.30 & 0.16 \\
17.11 & 0.13 & \\
\hline \hline
\end{tabular}

is smaller, and it produces flow uniformities and turbulence intensities similar to those of the tunnel at the Delft University of Technology.

\section{CUP ANEMOMETER CALIBRATION}

The characterization of the open test section has been completed using measurements with a calibrated cup anemometer. Having defined the uniform test section, the calibration procedure of the cup anemometer was carried out applying the standard IEC 61400-12-1 and procedures detailed in Refs. 30 and 31. In these experiments, the following instruments were used: a cup anemometer calibrated in the Wind Tunnel of Deutsche Wind Guard, Varel, Germany, four National Physical Laboratory $8 \mathrm{~mm}$ pitot tubes calibrated under laboratory accreditation requirements of the United Kingdom Accreditation Service (UKAS), four Setra C239 differential pressure transducers calibrated by NIST RPT 1500129433, and a NI compactDAQ-9172 chassis with a Digital I/O Module NI 9401 and Analog Input Modules NI 9215. The signals from the pitot tubes and cup anemometer are sampled at $5 \mathrm{kHz}$ during $60 \mathrm{~s}$ at every position of the defined working grid. The cup anemometer was located at $\mathrm{y}=0$ and $\mathrm{z}=0$ and the four pitot tubes at $\mathrm{y}=0.4 \mathrm{~m}, \mathrm{z}=0.4 \mathrm{~m} ; \mathrm{y}=-0.4 \mathrm{~m}, \mathrm{z}=0.4 \mathrm{~m} ; \mathrm{y}=0.4 \mathrm{~m}, \mathrm{z}=-0.4 \mathrm{~m}$; and $\mathrm{y}=-0.4 \mathrm{~m}$, $\mathrm{z}=-0.4 \mathrm{~m}$ (see Figs. 7 and 8 ).

Figure 9 shows the averaged measured velocity with the four pitot tubes with the cup anemometer located in the centre as illustrated in Figure 8. The flow velocities measured with the cup anemometer and the averaged measured velocities with the four pitot tubes without the cup anemometer are also included. Figure 9(a) corresponds to measurements performed without the false ceiling and Figure 9(b) to measurements with the ceiling. The comparison between Figures 9(a) and 9(b) shows that a better flow distribution is obtained with the false ceiling (i.e., the three values of the flow velocity are more coincident). Table III shows the relative errors between the averaged speeds measured with the pitot tubes and average speeds measured with the calibrated cup anemometer. The differences between the measurements of the pitot tubes without and with the cup anemometer placed in the working section are also included. 

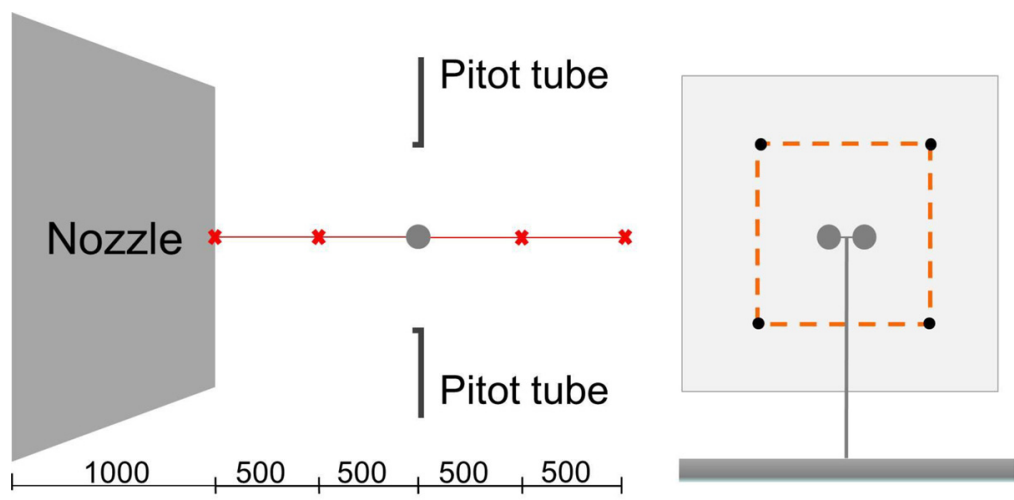

\section{Test section $\left(1500 \times 1500 \mathrm{~mm}^{2}\right)$ \\ L-I Uniform test section $\left(800 \times 800 \mathrm{~mm}^{2}\right)$}

* Measured positions

- Pitot tubes positions

- Cup anemometer calibrated

FIG. 7. Sketch of the positions of the pitot tubes and the cup anemometer. Dimensions are in millimeters.

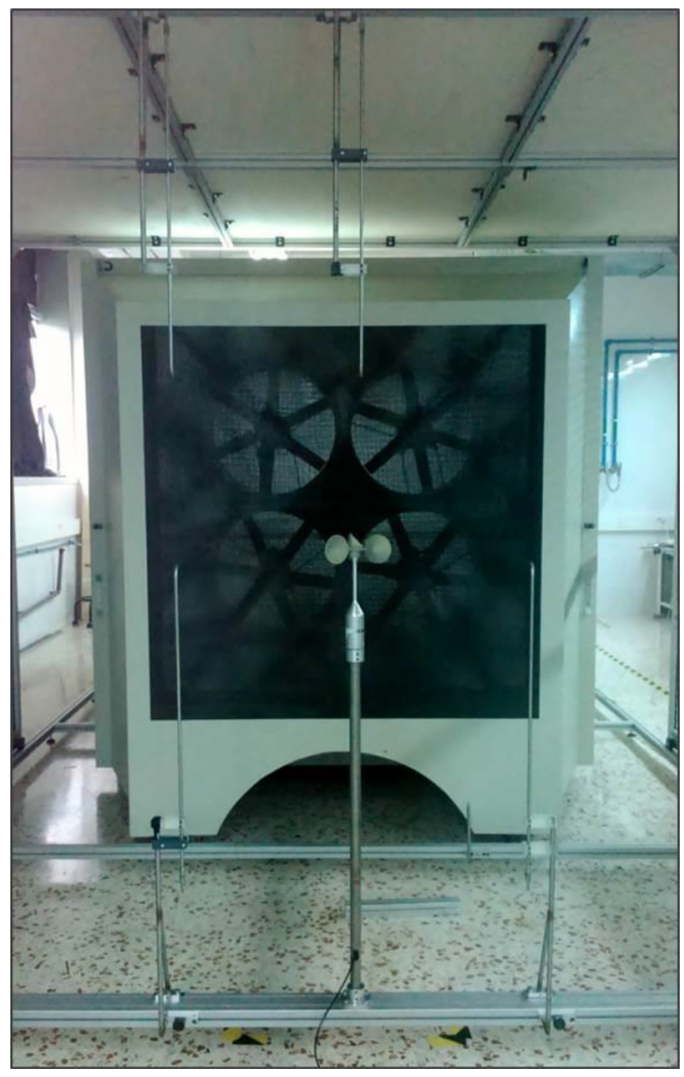

FIG. 8. The cup anemometer at the central position. 

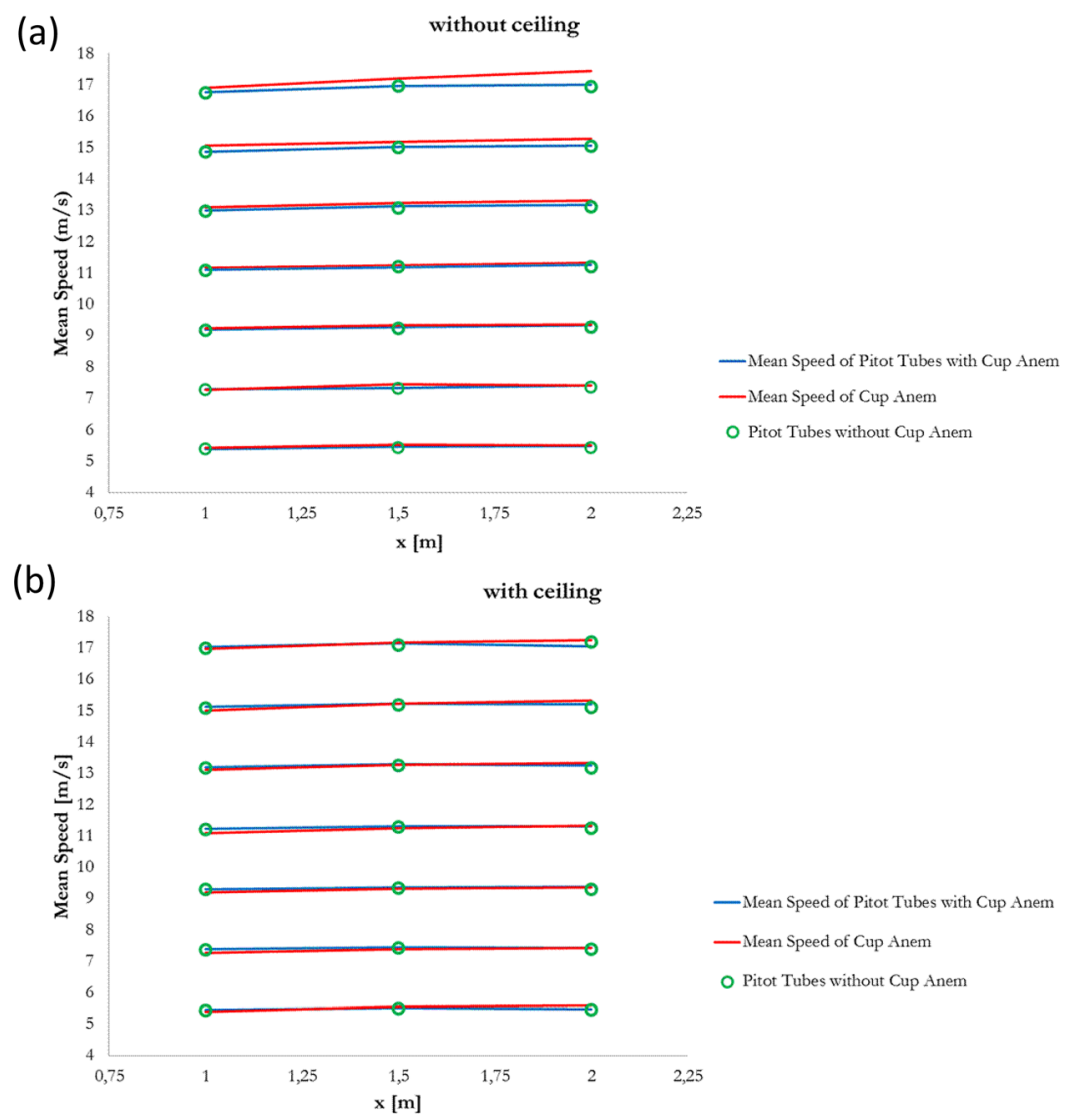

FIG. 9. Mean velocities at different positions from the de nozzle (x-axis). Blue lines: average velocities with 4 pitot tubes with the cup anemometer located at the center of the working section. Red lines: Measurements of the cup anemometer. Green circles: average of the measurements of the 4 pitot tubes without the cup anemometer.

Finally, the calibration results of the cup anemometer with the false ceiling are explained. The test conditions were as follows: wind tunnel exit area $=2.25 \mathrm{~m}^{2}$; anemometer frontal area $=0.022 \mathrm{~m}^{2}$, diameter of the mounting bar $=28 \mathrm{~mm}$, blockage ratio $=0.01$, temperature $=25.09 \pm 0.1^{\circ} \mathrm{C}$, atmospheric pressure $=1005 \mathrm{hPa} \pm 1.3 \mathrm{hPa}$, and relative air

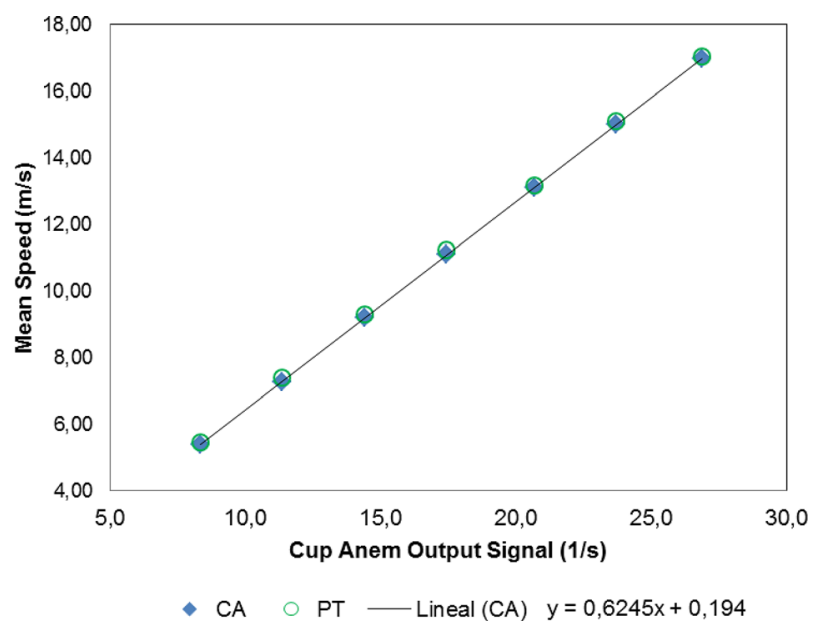

FIG. 10. Average speeds measured with the cup anemometer (CA), average speeds of the pitot tubes (PT), and linear fit obtained in the 4-Winds OJWT [Slope $=0.6242(\mathrm{~m} / \mathrm{s}) /(1 / \mathrm{s}) ;$ Offset $=0.297(\mathrm{~m} / \mathrm{s})]$. 
TABLE IV. Cup anemometer output signal (1/s), average speeds based on the linear fit of the certificate calibration $[$ Slope $=0.6245(\mathrm{~m} / \mathrm{s}) /(1 / \mathrm{s}) ;$ Offset $=0.194(\mathrm{~m} / \mathrm{s})]$, average tunnel speed between 4 pitot tubes positioned in every corner of the uniform test section, and relative errors between average speeds of pitot tubes and average speeds measured with the calibrated cup anemometer.

\begin{tabular}{lcccc}
\hline \hline $\begin{array}{l}\text { Measurement } \\
\text { number }\end{array}$ & $\begin{array}{c}\text { Cup anemometer } \\
\text { output signal }\left(\mathrm{s}^{-1}\right)\end{array}$ & $\begin{array}{c}\text { Tunnel speed based on the line fit } \\
\text { of the accredited certificate }(\mathrm{m} / \mathrm{s})\end{array}$ & $\begin{array}{c}\text { Average tunnel speed } \\
\text { of 4 pitot tubes }(\mathrm{m} / \mathrm{s})\end{array}$ & Err \% \\
\hline 1 & & & & \\
2 & 8.33 & 5.39 & 5.46 & 1.29 \\
3 & 11.34 & 7.28 & 7.38 & 1.43 \\
4 & 14.42 & 9.20 & 9.31 & 1.17 \\
5 & 17.45 & 11.09 & 11.23 & 1.26 \\
6 & 20.67 & 13.10 & 13.19 & 0.63 \\
7 & 23.72 & 15.00 & 15.12 & 0.75 \\
8 & 23.78 & 16.97 & 17.03 & 0.37 \\
9 & 23.78 & 15.04 & 15.10 & 0.39 \\
10 & 20.59 & 13.05 & 13.17 & 0.93 \\
11 & 17.47 & 11.10 & 11.23 & 1.15 \\
12 & 14.39 & 9.18 & 9.29 & 1.21 \\
13 & 11.37 & 7.30 & 7.37 & 0.97 \\
\hline \hline
\end{tabular}

humidity $=38 \% \pm 1 \%$. The best linear fit of the anemometer response was found when the cup anemometer was positioned at $\mathrm{x}=1 \mathrm{~m}$ from the nozzle exit. The line fit obtained was $y=0.6242 x+0.297$ (see Figure 10).

Table IV shows the cup anemometer output signal (1/s), the average speeds based on the linear fit of the certificate calibration $[$ Slope $=0.6245(\mathrm{~m} / \mathrm{s}) /(1 / \mathrm{s}) ;$ Offset $=0.194(\mathrm{~m} / \mathrm{s})]$, the tunnel speed averaged between the 4 pitot tubes located at the corners of the uniform test section, and relative errors between the averaged speeds measured with the pitot tubes and average speeds measured with the calibrated cup anemometer. The measurements were performed in a single experiment increasing the air speed from about $5 \mathrm{~m} / \mathrm{s}$ to $17 \mathrm{~m} / \mathrm{s}$ (measurements 1 to 7 ) and then decreasing the air speed down to $5 \mathrm{~m} / \mathrm{s}$ (measurements 8 to 13 ). It can be seen that the relative errors are less than $1.5 \%$.

\section{CONCLUSIONS}

Design criteria and layout options for an open jet wind tunnel have been discussed, and the performance characteristics of the facility have been shown in detail. The final design of the open jet tunnel is original, and it allows a good performance at a relatively low cost. The shape of the nozzle is not conventional, but flow shows appropriate characteristics in a central section of the jet with a cross section of $0.8 \mathrm{~m} \times 0.8 \mathrm{~m}$ and distances from the jet exit from $1 \mathrm{~m}$ to $2 \mathrm{~m}$. The characteristics of the tunnel show that it can be operated at constant average velocities and relatively low turbulence intensities. The analysis of the velocity signal, measured with a hot wire probe, indicates that the measured power spectrum has similar characteristics to those of the atmospheric turbulence. Simultaneous flow measurements with a calibrated cup anemometer and with pitot tubes distributed within the test section show that the tunnel can be used to test small scale wind turbines and for calibration purposes.

\section{ACKNOWLEDGMENTS}

The authors would like to thank Dr. Robert Gilabert and Dr. Anton Vernet for their valuable and constructive suggestions. Thanks are also extended to Valentín Sánchez for his valuable assistance in running wind tunnel tests. We would like to acknowledge the support of the Research 
Section Test and Measurements, DTU Wind Energy at Campus Risø in Roskilde, Denmark, in particular, for the special collaboration of Karen Enevoldsen in the data acquisition system optimization, and Dr. Søren Larsen, who assisted us in valuable discussion of the spectra and results. The tunnel was constructed by Orienta SI (www.orientasi.com). S.T., J.P., and I.C. acknowledge the financial support of the Spanish Ministerio de Economía y Competitividad under Grant No. CTQ2013-46799-C2-1-P.

${ }^{1}$ D. Sims-Williams and R. Dominy, "The design of an open-jet wind tunnel for model testing," in Proceedings of the 2002 SAE Motorsports Engineering Conference and Exhibition, Indianapolis, Indiana, USA, 2-5 December 2002 (SAE International, 2012), p. 382.

${ }^{2}$ S. Mertens, "Wind energy in the built environment: Concentrator effects of buildings," Ph.D. thesis (Technische Universiteit Delft, Netherlands, 2006).

${ }^{3}$ L. E. M. Lignarolo, D. Ragni, C. Krishnaswami, Q. Chen, C. J. Simão Ferreira, and G. J. W. van Bussel, "Experimental analysis of the wake of a horizontal-axis wind-turbine model," Renewable Energy 70, 31 (2014).

${ }^{4} \mathrm{~J}$. Yen and N. Ahmed, "Improving safety and performance of small-scale vertical axis wind turbines," Procedia Eng. 49, 99-106 (2012).

${ }^{5}$ M. C. Remillieux, R. A. Burdisso, and W. J. Devenport, "Preliminary screening of flow behavior around airfoils using a microphone phased array," J. Acoust. Soc. Am. 123, 3022 (2008).

${ }^{6} \mathrm{P}$. Bachant and M. Wosnik, "Performance measurements of cylindrical- and spherical-helical cross-flow marine hydrokinetic turbines, with estimates of exergy efficiency," Renewable Energy 74, 318 (2015).

${ }^{7}$ Y. Li and S. M. Calisal, "A discrete vortex method for simulating a stand-alone tidal-current turbine: Modeling and validation,” J. Offshore Mech. Arct. Eng. 132, 031102 (2010).

${ }^{8}$ I. Paraschivoiu, Wind Turbine Design With Emphasis on Darrieus Concept, 1st ed. (Polytechnic International, Montreal, Quebec, Canada, 2002).

${ }^{9}$ U. S. Paulsen, T. F. Pedersen, H. A. Madsen, K. Enevoldsen, P. H. Nielsen, J. Hattel, L. Zanne, L. Battisti, A. Brighenti, M. Lacaze, V. Lim, J. W. Heinen, P. A. Berthelsen, S. Carstensen, E.-J. de Ridder, G. van Bussel, and G. Tescione, "Deepwind an Innovative Wind Turbine Concept for Offshore," in Proceedings of EWEA 2011, Brussels, Belgium, 14-17 March 2011.

${ }^{10}$ A. Sedaghat, X. Liu, J. Whitty, and X. Tang, "Wind power of small wind turbines in turbulent open jets," Sci. Irania 19, 272 (2012).

${ }^{11}$ S. Hansen and E. Sorensen, "A new boundary layer wind tunnel at the Danish Maritime Institute," J. Wind Eng. Ind. Aerodyn. 18, 213 (1985).

${ }^{12}$ A. R. Wittwer, G. S. Welter, and A. M. Loredo-Souza, see http://dx.doi.org/10.5772/54088 for Statistical Analysis of Wind Tunnel and Atmospheric Boundary Layer Turbulent Flows (2013).

${ }^{13}$ J. Meseguer Ruiz and A. Sanz Andrés, Aerodinámica Básica (Garceta Grupo Editorial, Madrid, 2005).

${ }^{14}$ M. C. Remillieux, E. D. Crede, H. E. Camargo, R. A. Burdisso, W. J. Devenport, M. Rasnick, P. Van Seeters, and A. Chou, "Calibration and demonstration of the new Virginia Tech anechoic wind tunnel," AIAA Paper 2008-2911, 2008

${ }^{15} \mathrm{~J}$. Mathew, C. Bahr, B. Carroll, M. Sheplak, and L. Cattafesta, "Design, fabrication, and characterization of an anechoic wind tunnel facility," AIAA Paper 2005-3052, 2005.

${ }^{16}$ C. Hanson, M.S. thesis (Massachusetts Institute of Technology, 1967). See NASA Technical Report Server 83N20705 (NASA-TM-84585, L-15563, NAS 1.15:84585, NASA Langley Research Center), Hampton, VA, USA.

${ }^{17}$ J. Winkler, F. Z. Temel, and T. Carolus, "Concept, design and characterization of a small aeroacoustic wind tunnel facility with application to fan blade measurements," in Proceedings of the Fan Noise 2007, Lyon, France, 17-19 September 2007.

${ }^{18}$ R. Howell, N. Qin, J. Edwards, and N. Durrani, "Wind tunnel and numerical study of the small vertical axis wind turbine," Renewable Energy 35(2), 412 (2010).

${ }^{19}$ G. J. W. van Bussel, "The development of Turby ${ }^{\circledR}$, a small VAWT for the built environment," in Global Wind Energy Conference (TU Delft, Wind Energy Section, 2004).

${ }^{20}$ A. Pope and W. Rae, Low-Speed Wind Tunnel Testing (John Wiley \& Sons, USA, 1984), pp. 62-131.

${ }^{21}$ F. M. White, Fluid Mechanics (Mc Graw Hill, NY, 2010), p. 169.

${ }^{22}$ Y. A. Çengel and J. M. Cimbala, Fluid Mechanics Fundamentals and Applications (McGraw-Hill, NY, 2006), p. 185.

${ }^{23}$ D. W. Green and R. H. Perry, Perry's Chemical Engineers' Handbook (McGraw-Hill Education, Europe, NY, 2007).

${ }^{24}$ R. Mehta and P. Bradshaw, "Design rules for small low speed wind tunnels," Aeronaut. J. R. Aeronaut. Soc. 83, $443-449$ (1979).

${ }^{25}$ P. D. Welch, "The use of Fast Fourier Transform of the estimation of the power spectra: A method based on time averaging over short, modified periodograms," IEEE Trans. Audio Electroacoust. 15, 70 (1967).

${ }^{26}$ A. G. Davenport, "The spectrum of horizontal gustiness near the ground in high winds," Q. J. R. Meteorol. Soc. 87, 194 (1961).

${ }^{27}$ G. I. Taylor, “The spectrum of turbulence," Proc. R. Soc. London, Ser. A 164, 476-490 (1938)

${ }^{28}$ R. B. Stull, An Introduction to Boundary Layer Meteorology (Kluwer Academic Publishers, Dordrecht-Netherlands, 1988), ISBN: 90-277-2768-6.

${ }^{29}$ T. P. Chong, P. F. Joseph, and P. O. A. L. Davies, "Design and performance of an open jet wind tunnel for aero-acoustic measurement," Appl. Acoust. 70, 605 (2009).

${ }^{30}$ Oldenburg University, private communication (2011).

${ }^{31}$ Deutsche Wind Guard, private communication (2013).

${ }^{32} \mathrm{~N}$. Ahmed and N. Findanis, "Wind tunnel 'Concept of Proof' investigations in the development of novel fluid mechanical methodologies and devices," in Wind Tunnels and Experimental Fluid Dynamics Research, edited by J. C. Lerner (InTech, 2011), p. 135.

${ }^{33}$ S. Pindado, J. Cubas, and A. Sanz-Andrés, Sci. World J. 2013, 197325. 
${ }^{34}$ J. Meseguer, A. Sanz-Andrés, S. Franchini, and S. Pindado, in Proceedings of the 80 Congreso Iberoamericano De Ingeniería Mecánica Instalaciones de Aerodinámica Experimental para Ingeniería Civil de la Universidad Politécnica de Madrid, Cusco, Perú, 23-25 Octubre 2007, código 112.

${ }^{35}$ M. C. Remillieux, E. D. Crede, H. E. Camargo, R. A. Burdisso, W. J. Devenport, M. Rasnick, P. Van Seeters, and A. Chou, "Calibration and demonstration of the New Virginia Tech Anechoic wind tunnel," AIAA 2008-2911, 2008. 